Article

\title{
Trends of Research on Supply Chain Resilience: A Systematic Review Using Network Analysis
}

\author{
Jin Sung Rha \\ Department of Business Administration, Inha University, Incheon 22212, Korea; jinsungrha@inha.ac.kr
}

Received: 30 March 2020; Accepted: 22 May 2020; Published: 26 May 2020

\begin{abstract}
Researchers have defined resilient supply chain management in various ways and have analyzed and explained it using many managerial theories. Thus, identifying trends in existing studies could serve as a foundation for future supply chain resilience studies. However, despite the accumulation of a wide body of literature on resilient supply chains, few studies have analyzed the research trends systematically. Therefore, the present study aimed to synthesize and summarize research trends in the supply chain resilience domain using network analysis. The Scopus database and Google Scholar were used to search for research articles on supply chain resilience. We conducted an analysis by visually representing coauthorship, cocitation, PageRank, and keyword networks for 825 research articles and 1725 authors. This study identified the main topics, key articles, and major author groups of supply chain resilience research. The findings are expected to help expand the scope of research to a wide range of subfields in supply chain resilience research in the future.
\end{abstract}

Keywords: supply chain resilience; supply chain risk management; network analysis; research trend analysis

\section{Introduction}

Supply chain management (SCM) covers the functions of production planning, purchasing, production, distribution, and sales. It focuses on strategically managing a network of suppliers and buyers that engage in business transactions. With business environments' growing sophistication, SCM has become a determinant of business success. As supply chain (SC) networks become global and increasingly complex in structure, both scholars and practitioners are paying close attention to how to manage risk factors, such as SC disruption and quality control failures that occur within the SC. SC risk factors can also affect the overall global industry. For example, Boeing delayed the development of its Dreamliner 787 in 2007 by more than three years as its first-tier suppliers failed to provide parts of the desired quality [1]. In another example, the 2011 Great East Japan Earthquake resulted in SC disruption and many casualties, as auto-parts plants in Japan could not operate after the earthquake [2]. SC risk management is significantly associated with corporate sustainability. SC sustainability-related risks include environmental, social, and economic factors that originate both inside and outside an organization. Especially, external SC risks, mainly involving global pandemic, economic crisis, trade conflicts, and energy price volatility, have a severe impact on operational performances and bring SC disruptions. Since global SCs are going to get more complicated and face more uncertainties and variabilities, firms would desire to continuously develop and enhance SC risk management processes. In this sense, researchers began to shed light on why SC risk management practices are vital for future sustainability and how organizations can foster healthier and more resilient SCs.

Research on SC risk management has been in full swing since the 1990s [3]. The general risk management of a company includes both its efforts to prevent crisis situations by proactively recognizing and managing potential risks, and the response and recovery efforts once a company faces a crisis situation despite efforts to prevent it. While preventing crisis situations is of the utmost importance, it is 
virtually impossible to eliminate all risks completely and to have perfect control of risks. According to the normal accident theory, from this perspective, no systems can completely avoid risks, and therefore, must bear a certain level of risk [4]. As in the case of the Three Mile Island nuclear incident, accidents can occur due to minor errors or chance, despite systematic management, and the damage increases if too much confidence is placed in the system or in the event of an unforeseen crisis situation [5].

A well-organized system runs the risk of incidents due to its internal structure and operational complexity. Based on theories and practical guidelines on SCM, modern SCs are managed very systematically. However, normal accident theory can also be applied to SCs. It has become routine practice to produce even a single product with raw materials and parts supplied from dozens of countries. As complexity increases in the SC due to globalization, companies may face risks, such as the failure of the SC and quality control due to, for example, natural disasters and disputes between suppliers, even when they have excellent SCM systems. Therefore, it is crucial to minimize damage and recover through resilient operation when unforeseen SCM crises occur. In this sense, $\mathrm{SC}$ resilience has been noted as a major element of risk management. An organization's resilience generally refers to its capacity to respond quickly to various situational changes. SC elasticity primarily describes how quickly an SC can recover effectively when it collapses due to unforeseen internal and/or external factors. SC resilience is significantly associated with sustainable SCM. Sustainable SCM can be defined as "the strategic, transparent integration and achievement of an organization's social, environmental, and economic goals in the systemic coordination of key interorganizational business processes for improving the long-term economic performance of the individual company and its SC" [6] (p. 368). The high number of papers on sustainable SCM domain explored green topics and the terms "sustainable SCM" and "green SCM" have been used interchangeably [7]. However, recently researchers started paying more attention to the relationship between SC resilience and SC sustainability. Resilience to face the vulnerability and risks from global markets plays a critical role in building sustainability and contingency planning, for both the upstream and downstream SC facilitates sustainable SCM [8,9].

Research on SC resilience has focused on the antecedents for building SC resilience, recovery through resilience in crisis, and the relationship between resilience and organizational performance. Many researchers have defined resilient SCM in various ways and have analyzed and explained it using many managerial theories. Thus, identifying trends in existing studies could serve as a foundation for future $\mathrm{SC}$ resilience studies. However, despite the accumulation of a wide body of research on resilient $\mathrm{SC}$, few studies have analyzed the research trends systematically. Therefore, the present study aimed to synthesize and summarize research trends in the SC resilience domain using network analysis. Unlike conventional trend analysis, which involves simply listing and analyzing research by classifying target studies based on their theories and variables, network analysis enabled us to conduct various research topic analyses by constructing a network of keywords that represent each paper. In addition, network analysis allowed us to cluster research topics and to determine major contributing studies based on the network analysis of coauthorship and cocitation.

The rest of the present paper is organized as follows. Section 2 reviews previous studies on SC resilience. Section 3 describes the network analysis method for research trends. Network analysis was performed using Netminer 4 . Section 4 presents the study results. Section 5 discusses the findings and implications of this study, its limitations, and future research directions.

\section{SC Resilience}

Holling [10] (p. 15) first used the term "resilience" in his ecology research and defined it as the ability to maintain "the same relationships between populations or state variables" while absorbing various internal and external environmental changes and disturbances due to accidents and adhering to the system's original state. Researchers have also become interested in resilience from a management standpoint, as they have recognized the turbulence of the management environment. Hamel and Välikangas [11] defined resilience as the capacity to continually restore a system and argued that such 
capacity is required for innovation and new value creation processes. Sheffi [12] defined corporate resilience as the capacity to successfully confront unforeseen situations. Sutcliffe and Vogus [13] stated that resilience has two primary characteristics: the capacity to absorb and minimize the burden of risk when a crisis occurs and the capacity to recover even if the system goes down due to unforeseen disaster.

SCM researchers have focused on SC disruption and vulnerability by noting the concept of resilience. They have defined SC resilience as the capacity to quickly and effectively restore to a normal situation or to minimize negative consequences when crises arise, such as when the business transactions between members of a SC are disrupted due to unexpected natural disaster, accident, or rapid change in the market and industry [12]. A resilient SC has more capacity than the existing system to restore to a prerisk state, to build a more stable and innovative SCM system [14,15], and to make the SC network sustainable [16]. SC resilience sometimes includes SC robustness, which refers to the capacity to operate as usual even if disturbances occur along the SC, while resilience indicates the capacity to recover from the negative consequences of SC disturbance [17].

Considering that successful risk management depends on SC resilience, how can companies make their SCs resilient? Blackhurst et al. [18] argued that a resilient SC is built in three stages: (1) recognize the problem quickly; (2) develop an appropriate recovery plan; and (3) redesign the SC to ensure resilience. Lee [19] suggested that the successful management of volatility and complexity of a global SC requires "triple-A" (agility, adaptability, and alignment). Christopher and Peck [20] argued that building a healthy SC requires creating a culture of SC reengineering, cooperation, and risk management.

In summary, many studies have pointed out that resilient SCs can be built through flexibility, visibility, and collaboration $[19,21,22]$. Flexibility is the capacity to accommodate environmental changes without breaking and to reconfigure resources effectively according to the situation. Visibility is the ability to sense turbulence in real-time or quickly [23]. Collaboration refers to sharing valuable and important information among companies; the stronger the collaboration between companies in an SC, the faster their response to changes $[24,25]$. Thus, SCs operate more resiliently when all companies come together to overcome crises than when only one company makes effort to do so [26]. In addition, SC decision-making and application processes need to be very fast [15] and companies in SCs need to have common goals that benefit all parties in the SC [27]. SC resilience may also develop from information-sharing capacity [28], organizational structure and culture [29,30], and convergence of how the existing SC operates with new policies and technologies [24]. Moreover, SC resilience is not developed in one instant, but is a product of the learning that organizations gain from experiences with crises [21]. These capacities that comprise a resilient SC have a significantly positive impact on improving an organization's overall performance and effectively reducing the negative impact of disruption and SC vulnerability through competitive advantages [22].

SC resilience capabilities allow firms to make their SCs healthier and more sustainable. The economic sustainability of many firms is menaced due to incapability to handle unexpected events, complexity, and vulnerability in SC $[8,9]$. Collaboration with suppliers and partners to strengthen SC resilience include risk sharing agreements, joint continuity plans, and hedging risks with SC hubs $[21,26]$. In addition, some firms set up risk knowledge management to monitor thoroughly the possibility of unexpected events from the various SC risks [15]. These efforts significantly enhance SC flexibility, velocity, visibility, and agility, enabling SC integration [24]. Previous case studies showed that the firms that embedded resilience practices within their SCs survived by recovering from the serious disasters and coming back with better performances despite the global economic crisis [15,31].

\section{Analyzing Research Trends with Network Analysis}

Network analysis is an analytic technique that involves modeling the real world and the systems created by various types of individual units, such as humans, organizations, and objects, into network diagrams with nodes and links for the relationships between nodes. This study analyzed the trends in SC resilience research by text analysis based on co-occurring keywords, coauthor network analysis, and 
cocitation and PageRank analysis. Conventional research trend analysis generally involves classifying research topics based on the researcher's subjective judgment or classifying research articles according to their methodology, and then presenting descriptive statistics as the study results. By contrast, analysis of research trends using networks excludes the subjectivity of the researcher and extracts meaningful elements, such as coauthorship, citations, cocitations, and keywords, from the text; network analysis has also been used lately in trend analyses of SCM research [3,32-34]. Prior studies [3,32] explored the most contributing research articles on SC issues, such as SC risk management and eco-friendly SCM, using PageRank values based on directional citation networks. Cocitation analysis reflects the knowledge base of a particular SC domain [33,34].

The most widely used bibliometric network analysis is keyword network analysis or text network analysis. This is a combination of text analysis and network analysis, and can be used for a wide variety of texts, including media articles, speeches, reports, and research articles [35]. In network analysis, a network, in which nodes represent each paper's characteristics (e.g., keywords, author, and institution), is built before the analysis is performed. A text element must be selected for use in the analysis. In research trend analysis, the elements are often authors, citations, and keywords. In the present study, we used the keywords of each paper for network analysis. The network analysis with keywords was conducted as follows. First, we entered the keywords listed in each paper to create a data set with two variables: paper and keyword. Second, we built a two-mode network using the keyword data, where keywords are not directly linked together but are linked with individual research articles. For example, if the keyword "A" is listed as a keyword in several papers, it is linked to several papers and the link is not directional. Third, we converted the two-mode network consisting of research articles and keywords into a one-mode network, which consisted of just keywords. There are various types of algorithm for converting a two-mode network to a one-mode network. In this study, we carried out the conversion using cosine similarity, which builds a network around the co-occurrence of keywords. For example, if the keywords " $\mathrm{A}$ " and " $\mathrm{B}$ " are both listed in several research articles, they are linked when the network is built, as they are considered closely related. In this manner, a one-way network consisting of just keywords can be constructed. Fourth, we performed various analyses using the keyword network. In this study, we constructed a word cloud based on the frequency of keyword occurrences and mapped the network into a spring map. In addition, to identify major keyword nodes, we calculate each node's degree centrality and betweenness centrality. The degree centrality and betweenness centrality are calculated for each keyword node. Finally, we perform clustering to observe whether keywords form clusters; this can be used to identify major research topic groups.

Research trend analysis with a coauthorship network is very similar to keyword network analysis. We constructed a two-mode network with individual research articles and authors as nodes, instead of keywords, and then converted it into a one-mode network with just authors based on co-occurrence; finally, we calculated centrality and clustering. Network analysis can also be performed by constructing nodes just for research articles. There are two ways to construct a research article network. The first method involves building a two-mode network of citing articles and cited articles based on the cocitation of research articles, and then converting this into a one-mode network with just cited articles for analysis. This allows the clustering of cited articles. The second method involves building a network based on mutual citations; unlike other networks, a citation network is directional. In this study, we performed a PageRank analysis based on mutual citations. The methods used for analyzing research trends with network analysis are summarized in Table 1. 
Table 1. Methods used for research trends analysis.

\begin{tabular}{|c|c|c|}
\hline Types of Networks & & Steps \\
\hline \multirow{8}{*}{ Keywords or Authors Network } & 1. & Selection of database and articles \\
\hline & & - $\quad$ Scopus (1998 2017) \\
\hline & 2. & Creating a nondirectional two-mode network \\
\hline & & $\begin{array}{l}\text { - Relationship between article nodes and } \\
\text { keyword nodes (or author nodes) }\end{array}$ \\
\hline & 3. & $\begin{array}{l}\text { One network conversion using cosine similarity } \\
\text { or inner product }\end{array}$ \\
\hline & & $\begin{array}{l}\text { - Constructed by keyword nodes (or } \\
\text { author nodes) }\end{array}$ \\
\hline & 4. & Network analysis \\
\hline & & $\begin{array}{ll}\text { - } & \text { Centrality analysis } \\
\text { - } & \text { Clustering analysis (community analysis) }\end{array}$ \\
\hline \multirow{6}{*}{ Citation Network } & 1. & Selection of database and articles \\
\hline & & - $\quad$ Scopus (1998 2017) \\
\hline & 2. & Creating a directional one-mode network \\
\hline & & - $\quad$ Constructed by article nodes \\
\hline & 3. & Network Analysis \\
\hline & & - $\quad$ PageRank \\
\hline
\end{tabular}

\section{Analysis}

\subsection{Subjects}

In this study, the Scopus academic database was used to search for research articles on SC resilience. Scopus was created by Elsevier publisher in 2004. It is very useful for searching for articles in the field of management. The searched keywords were chosen based on previous research and included "resilient SC", "SC resiliency", "SC disruption", "SC recovery", "SC robustness", and "SC risk mitigation". In the search results, we limited subject areas to business and engineering, and searched for articles published up to 2017. We included articles published only in English and excluded proceedings and books; this yielded 808 research articles.

While Scopus is a representative academic database that includes major journals from around the world, it does not include all major published research papers. For example, the Journal of Business Logistics has published a number of major research papers on SCs but Scopus does not include its articles published before 2012; therefore, the articles were excluded from our search. As the main purpose of this study was to capture research trends, major articles had to be included in the analysis. Since Scopus is not exhaustive in terms of listing published research articles, we also searched Google Scholar for research articles to fill the gaps. With an additional 17 research articles identified by searching on Google Scholar, 825 research articles were included in the analyses.

Figure 1 shows the distribution of publication years for the 825 research articles. According to Scopus, the first research article on SC resilience was published in 1998. Since then, the number of SC resilience papers has steadily increased over time, particularly since 2010. Table 2 shows the journals that published at least 10 papers on SC resilience. As shown in Table 2, the International Journal of 
Production Economics and the International Journal of Production Research are representative journals that published articles on SC resilience.

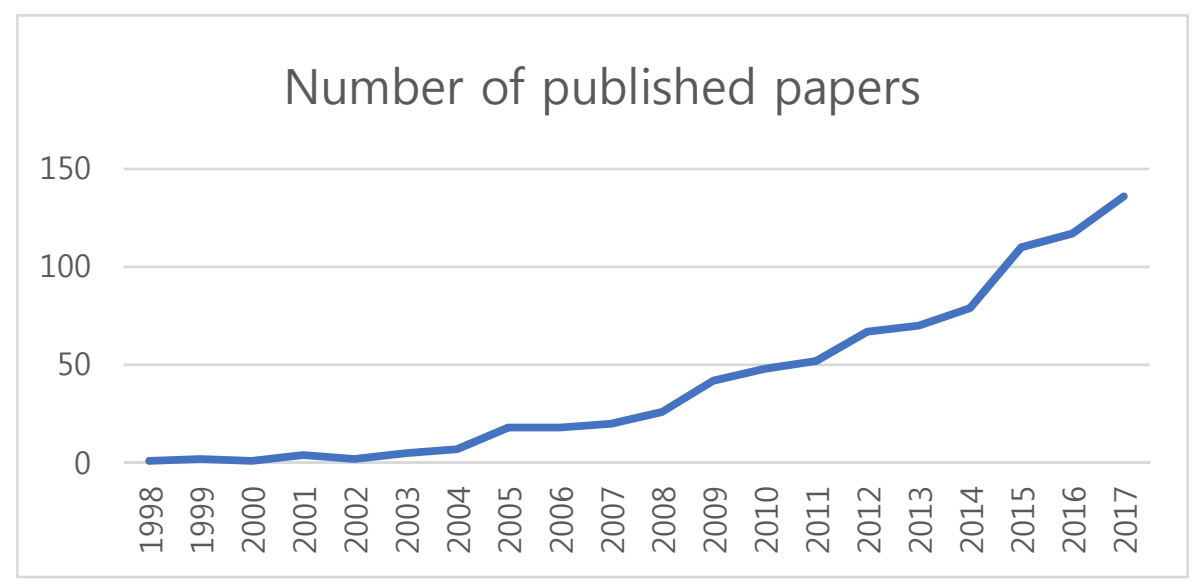

Figure 1. Numbers of published supply chain (SC) resilience papers.

Table 2. Major journals publishing SC resilience articles.

\begin{tabular}{cc} 
Source Title & Number of Papers \\
\hline International Journal of Production Economics & 113 \\
International Journal of Production Research & 99 \\
Journal of Cleaner Production & 43 \\
Supply Chain Management & 37 \\
International Journal of Logistics Systems and Management & 27 \\
Production Planning and Control & 26 \\
International Journal of Physical Distribution and Logistics Management & 26 \\
International Journal of Logistics Management & 27 \\
Oransportation Research Part E Logistics and Transportation Review & 25 \\
Journal of Manufacturing Technology Management & 17 \\
International Journal of Logistics Research and Applications & 15 \\
International Journal of Supply Chain Management & 15 \\
Journal of Operations Management & 12 \\
Management Science & 13 \\
Journal of Business Logistics & 11 \\
Production and Operations Management & 12 \\
Industrial Management and Data Systems & 12 \\
International Journal of Operations and Production Management & 9 \\
IEternational Transactions in Operational Research & 9 \\
Journal of the Operational Research Society & 9 \\
Internat of Supply Chain Management & 9 \\
\hline
\end{tabular}

Table 3 shows the top contributing organizations among the research institutions with which authors of SC resilience articles were affiliated. The table suggests that studies were generally conducted at institutions in the United States and Europe. 
Table 3. Major organizations that contribute to SC resilience research.

\begin{tabular}{lc}
\hline \multicolumn{1}{c}{$\quad$ Affiliation } & Number of Papers \\
\hline Cranfield University, UK & 21 \\
Michigan State University, US & 17 \\
Auburn University, US & 13 \\
Syddansk Universitet, DK & 12 \\
Pennsylvania State University, US & 11 \\
Hong Kong Polytechnic University, HK & 11 \\
Iowa State University, US & 10 \\
Cardiff University, UK & 10 \\
ETH Zurich, CH & 10 \\
Hochschule für Wirtschaft und Recht Berlin, DE & 10 \\
Arizona State University, US & 9 \\
Nanyang Technological University, SG & 9 \\
AGH University of Science and Technology, PL & 9 \\
University of Tehran, IR & 9 \\
Politecnico di Milano, IT & 9 \\
Indian Institute of Technology, Bombay, IN & 8 \\
University of Tennessee, Knoxville, US & 8 \\
Ohio State University, US & 7 \\
University of Massachusetts, Dartmouth, US & 7 \\
Iran University of Science and Technology, IR & 7 \\
East Carolina University, US & 7 \\
Chinese Academy of Sciences, CN & 7 \\
University of California, Berkeley, US & 7 \\
University Michigan, Ann Arbor, US & 7 \\
Indian Institute of Technology Delhi, IN & 7 \\
Universite Concordia, CA & 7 \\
St. Petersburg Institute for Informatics and Automation, Russian Academy of Sciences, RU & 7 \\
\hline & \\
\hline
\end{tabular}

\subsection{Coauthorship}

Network analysis was conducted to analyze the relationship, influence, and community structure among the authors of research articles. The analysis involved the following steps. First, we extracted the authors' names from each article and built a matrix for network analysis. To construct the matrix, we plotted a two-mode network with research papers and keywords that showed which authors appear in each paper. For example, when there are six authors from five papers, as shown in Table 4, a two-mode network can be constructed, as shown in the left-hand side of Figure 2. Each article must have no duplicate author names. The co-occurrence of authors $\mathrm{A}$ and $\mathrm{C}$ in Articles 1 and 3 means that $\mathrm{A}$ and $\mathrm{C}$ are linked due to their similarity in this relationship during the conversion of the two-mode network into the one-mode network consisting only of authors, as shown on the right-hand side of Figure 2. Since authors B and A have never worked together on a research article, they are not linked in a one-mode network. Links in this one-mode network are not directional; the value of a link between the same keywords is 0 ; the same keywords are not linked in the network. Finally, after building the network, we performed analyses, such as centrality analysis and clustering, to determine the influential authors and research groups.

Table 4. Author occurrence data by article.

\begin{tabular}{clll}
\hline Article & \multicolumn{4}{c}{ Authors (A, B, C, D, E, and F) } \\
\hline 1 & A & C & \\
2 & B & C & F \\
3 & A & C & D \\
4 & E & F & \\
5 & A & F & \\
\hline
\end{tabular}




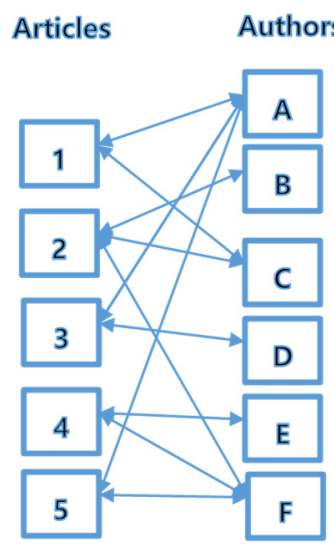

Two-mode Network

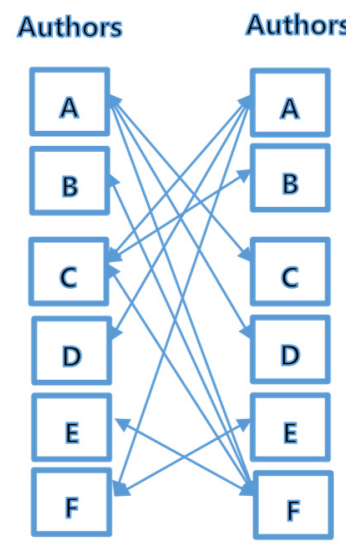

One-mode Network

Figure 2. A two-mode network of articles and authors and a one-mode network of authors.

In this study, we conducted our analysis by visually representing coauthorship for the 825 research articles in networks. Figure 3 shows a schematic of two-mode networks between 825 articles and 1725 authors, including several disconnected networks. Figure 4 shows an enlarged view of part of the networks. In Figure 4, a square node represents an author and a circular node represents an article. While the two-mode network had no links between authors, its conversion into a one-mode network with just authors allowed us to determine coauthorship links and clustering of authors on research topics.

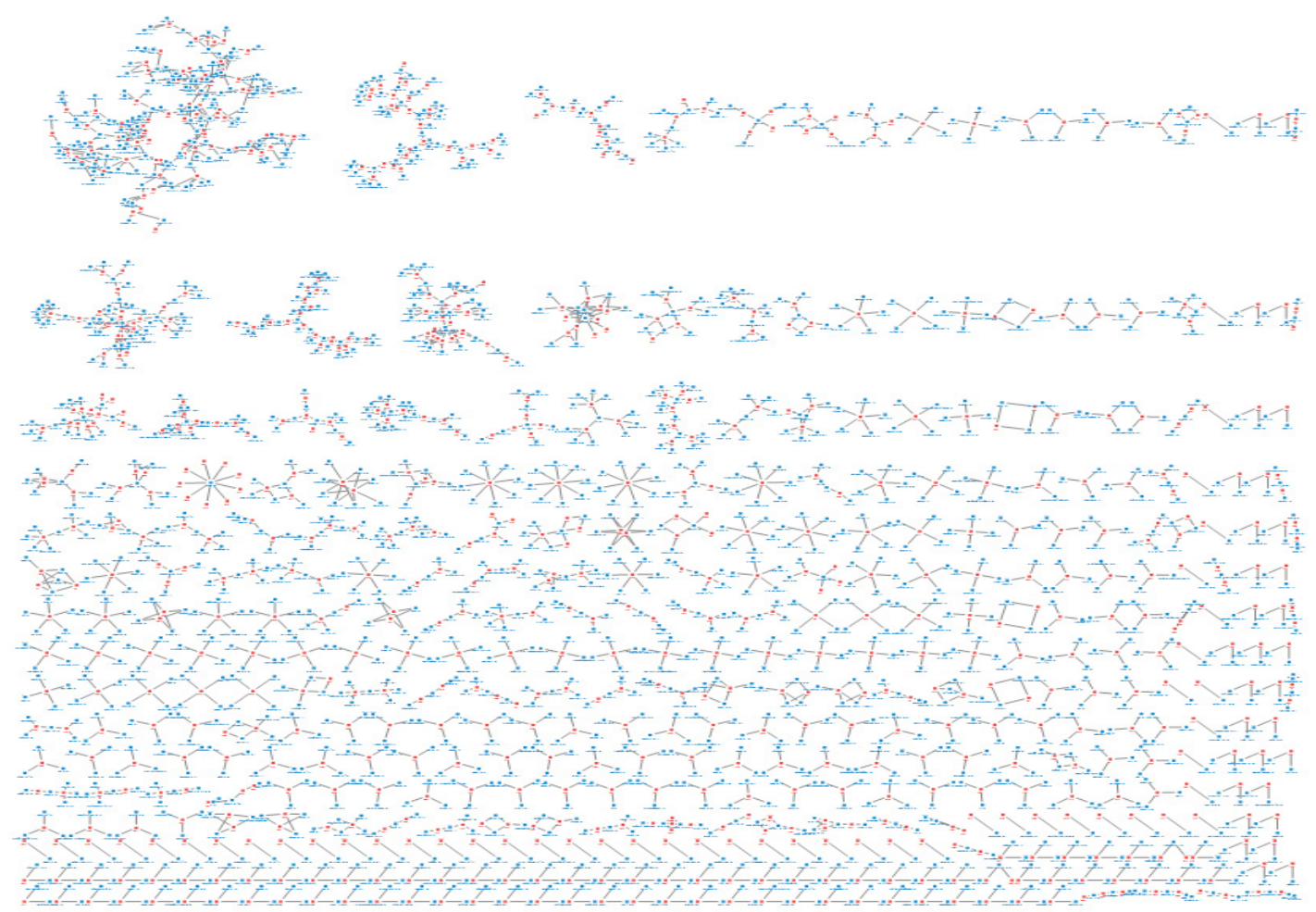

Figure 3. Two-mode network between authors and research articles. 


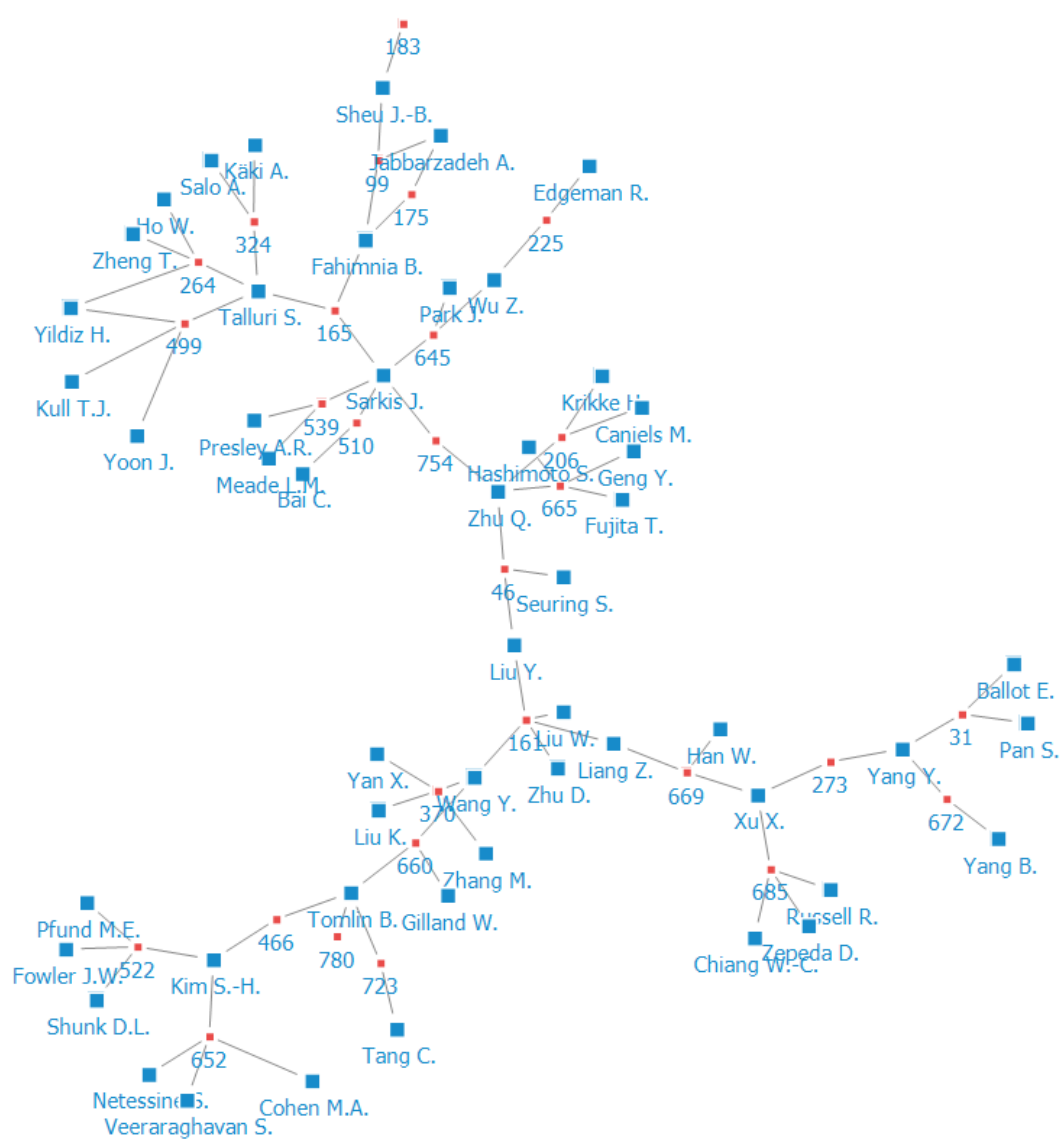

Figure 4. Two-mode network between authors and research articles (partial magnification).

Before converting the two-mode network of articles and authors into a one-mode network, we analyzed the two-mode network. Table 5 shows those among the 1725 authors of 825 articles who authored at least five of the articles. The one-mode network of major authors was built with 337 authors who had authored at least two of the articles. The conversion was conducted using the inner product.

Table 5. Major authors publishing SC resilience articles.

\begin{tabular}{cc}
\hline Author & Number of Articles \\
\hline Wagner, S.M. & 11 \\
Kumar, S. & 11 \\
Govindan, K. & 11 \\
Ivanov, D. & 10 \\
Sawik, T. & 9 \\
Blackhurst, J. & 8 \\
Craighead, C.W. & 8 \\
Christopher, M. & 8 \\
Sokolov, B. & 7 \\
Li, J. & 6 \\
Zsidisin, G.A. & 6 \\
Gunasekaran, A. & 6 \\
Dolgui, A. & 6 \\
Hanna, J.B. & 5 \\
Autry, C.W. & 5 \\
Jain, V. & 5 \\
Xiao, T. & 5 \\
Cruz-Machado, V. & 5 \\
Sarkis, J. & 5 \\
\hline
\end{tabular}


The value of the inner product equals the number of coauthored articles between two authors; in this study, only coauthorships that occurred at least twice were included in the analysis:

$$
\text { Inner Product }=\sum_{k=1}^{n} \mathrm{C}_{\mathrm{ik}} \mathrm{C}_{\mathrm{jk}}
$$

where $C_{j k}$ is whether author $j$ appeared in article $k$.

To analyze each author's influence and importance, we calculated the degree centrality and betweenness centrality of individual nodes in the network. The degree centrality of a node is the number of nodes with a direct link to the node and indicates each node's local centrality in the network. In network text analysis, an author with a higher degree centrality is linked to many other authors and thus, can be interpreted as a representative author of a research group.

Degree centrality was calculated using:

$$
\text { Degree Centrality }=\frac{\sum \text { Weight of Incident Links }}{\text { Number of Nodes }-1} .
$$

Betweenness centrality is a measure of the degree to which a node plays the role of mediator in a network. Thus, an author with high betweenness centrality can be interpreted as having a strong influence on other authors.

Betweenness centrality was obtained using:

$$
\text { Betweenness Centrality }=\frac{\sum_{\mathrm{jk}} \mathrm{g}_{\mathrm{jk}}\left(\mathrm{n}_{\mathrm{i}}\right) / \mathrm{g}_{\mathrm{jk}}}{\left[\frac{(\mathrm{g}-1)(\mathrm{g}-2)}{2}\right]},
$$

where $g_{j k}=$ number of shortest paths between nodes $j$ and $k, g_{j k}\left(n_{i}\right)=$ the number of shortest paths between nodes $\mathrm{j}$ and $\mathrm{k}$ that include node $\mathrm{I},[(\mathrm{g}-1)(\mathrm{g}-2) / 2]=$ the number of node pairs that do not include $\mathrm{n}_{\mathrm{i}}$.

Tables 6 and 7 present the results.

Table 6. Results of degree centrality analysis (coauthorship network).

\begin{tabular}{cc}
\hline Authors & Degree Centrality \\
\hline Govindan, K. & 0.03869 \\
Craighead, C.W. & 0.02381 \\
Wang, S. & 0.020833 \\
Blackhurst, J. & 0.020833 \\
Wagner, S.M. & 0.020833 \\
Kumar, S. & 0.020833 \\
Li, J. & 0.017857 \\
Autry, C.W. & 0.017857 \\
Diabat, A. & 0.017857 \\
Agarwal, A. & 0.017857 \\
Kumar, V. & 0.017857 \\
Jha, P.C. & 0.017857 \\
Hanna, J.B. & 0.014881 \\
Melnyk, S.A. & 0.014881 \\
Stankovski, S. & 0.014881 \\
Ostojić, G. & 0.014881 \\
Gošnik, D. & 0.014881 \\
Milisavljević, S. & 0.014881 \\
Delić, M. & 0.014881 \\
Beker, I. & 0.014881 \\
Kannan, D. & 0.014881 \\
\hline
\end{tabular}


Table 6. Cont.

\begin{tabular}{cc}
\hline Authors & Degree Centrality \\
\hline Gunasekaran, A. & 0.014881 \\
Lai, K.K. & 0.014881 \\
Sonnemann, G. & 0.014881 \\
Tuma, A. & 0.014881 \\
Thorenz, A. & 0.014881 \\
Gemechu, E.D. & 0.014881 \\
Helbig, C. & 0.014881 \\
Young, S.B. & 0.014881 \\
Sokolov, B. & 0.014881 \\
Dolgui, A. & 0.014881 \\
Ivanov, D. & 0.014881 \\
\hline
\end{tabular}

Table 7. Results of betweenness centrality analysis (coauthorship network).

\begin{tabular}{cc}
\hline Authors & Degree Centrality \\
\hline Govindan, K. & 0.000622 \\
Wagner, S.M. & 0.000302 \\
Zsidisin, G.A. & 0.000178 \\
Diabat, A. & 0.00016 \\
Jha, P.C. & 0.00016 \\
Ivanov, D. & 0.000077 \\
Craighead, C.W. & 0.000071 \\
Kumar, S. & 0.000053 \\
Qi, X. & 0.000018 \\
Loh, H.S. & 0.000018 \\
Christopher, M. & 0.000018 \\
Jolai, F. & 0.000018 \\
Pavlov, A. & 0.000006 \\
Sokolov, B. & 0.000006 \\
\hline
\end{tabular}

Table 8 shows the clusters with at least five authors in close research collaboration according to the results of clustering in the one-mode network with authors. Authors within a cluster are listed in order of degree centrality starting with the highest degree centrality.

Table 8. Clusters by authors (coauthorship network).

\begin{tabular}{|c|c|}
\hline Cluster & Authors \\
\hline 1 & $\begin{array}{l}\text { Govidan, K., Jha, P.C., Carvalho, H., Azevedo, S.G., Cruz-Machado, V., Agarwal, V., } \\
\text { Darbari, J.D., Fattahi, M., Abdallah, T., and Garg, K. }\end{array}$ \\
\hline 2 & $\begin{array}{l}\text { Wagner, S.M., Zsidisin, G.A., Mizgier, K.J., Ragatz, G.L., Juttner, M.P., Bode, C., Neshat, N., } \\
\text { and Melnyk, S.A. }\end{array}$ \\
\hline 3 & Ivanov, D., Pavlov, A., Sokolov, B., Dolgui, A., and Ivanova, M. \\
\hline 4 & Craighead, C.W., Handfield, R.B., Blackhurst, J., Wowak, K.D., and Ketchend, D.J. \\
\hline 5 & Sonnemann, G., Tuma, A., Thorenz, A., Gemechu, E.D., Helbig, C., and Young, S.B. \\
\hline 6 & Ostojic, G., Gonsnik, D., Milisavljevic, S., Delic, M., Beker, I., and Stankovski, S. \\
\hline
\end{tabular}

\subsection{PageRank Analysis}

Many research trend analysis studies have classified major articles based on how often they have been cited. However, this does not reflect a paper's relative importance. Therefore, recent research trend analysis studies have identified influential papers using the PageRank method, which involves assigning weights according to a research article's relative importance. PageRank is used in search engines to rank the influence of major web pages using search terms. The more often a paper is cited by influential papers, the higher its PageRank value. The number of articles that cite a specific paper can 
be obtained by normalizing the number of links to the paper [36,37]. In this study, we identified mutual citations in 825 research articles. The links in the network are directional and each has a weight of 1. This means that article A can cite article B only once. The PageRank centrality value was calculated according to the method proposed by Brin and Page [36]. Figure 5 shows a concentric map based on the values. The closer an article is to the map's center, the larger the PageRank centrality value. The results of the PageRank analysis show that a few of the 825 articles had a high PageRank value, while most other articles had similar PageRank values. Table 9 shows the major papers with high PageRank values.

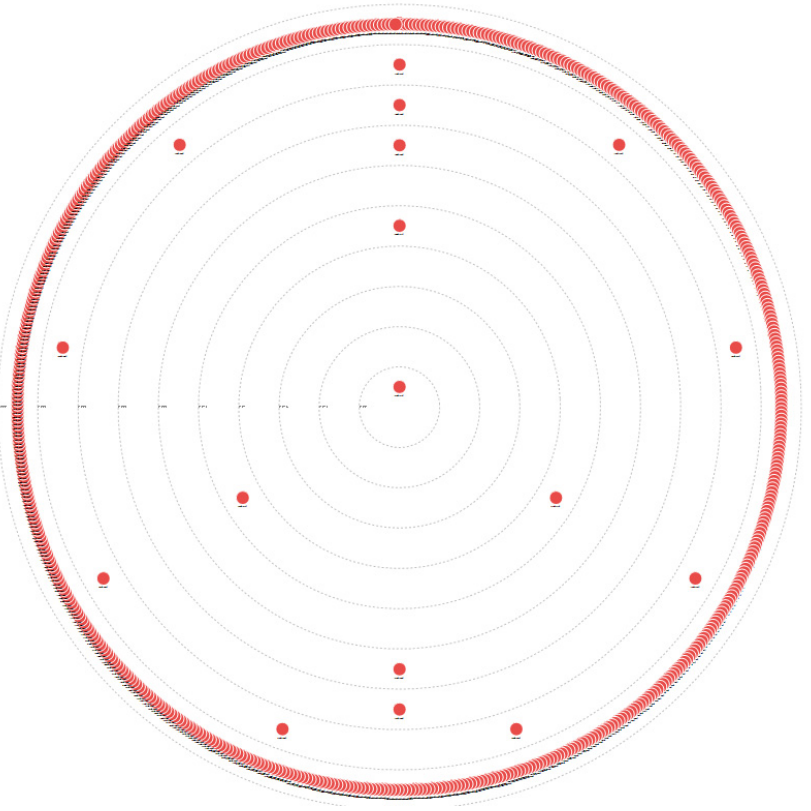

Figure 5. Concentric map of PageRank analysis.

Table 9. Results of PageRank analysis.

\begin{tabular}{cccc}
\hline Authors & PageRank Centrality & Local Citation & Global Citation \\
\hline Sheffi [12] & 0.023343 & 32 & 765 \\
Jüttner et al. [38] & 0.013424 & 85 & 1180 \\
Kleindorfer and Saad [39] & 0.012898 & 142 & 1553 \\
Christopher and Peck [20] & 0.011997 & 153 & 1786 \\
Christopher and Lee [40] & 0.008174 & 91 & 973 \\
Craighead et al. [41] & 0.008068 & 121 & 878 \\
Tomlin B. [42] & 0.006055 & 72 & 952 \\
Hendricks and Singhal [43] & 0.005662 & 71 & 1072 \\
Tang [44] & 0.004845 & 70 & 394 \\
Blackhurst et al. [18] & 0.004081 & 62 & 600 \\
Sheffi and Rice [45] & 0.004053 & 53 & 817 \\
Peck [46] & 0.003591 & 34 & 819 \\
Fleischmann et al. [47] & 0.003506 & 14 & 305 \\
Tang [48] & 0.0034 & 40 & 507 \\
Babich et al. [49] & 0.00281 & 27 & 516 \\
Faisal et al. [50] & 0.002589 & 35 & 363 \\
Zsidisin et al. [51] & 0.002465 & 14 & 794 \\
Knemeyer et al. [52] & 0.002379 & 50 & 793 \\
Manuj and Mentzer [53] & 0.002273 & 43 & 648 \\
Jüttner [54] & 0.001935 & 37 & 213
\end{tabular}




\subsection{Cocitation Analysis}

The similarity between research articles can be determined by analyzing their cocitations. This analysis involves building a two-mode network of citing articles and cited articles and then converting it into a one-mode network. Clustering cited articles in a one-mode network yields similar article groups, because papers with similar research methods or topics are cited together. In our study, we included only articles that were cited together more than 10 times. The bibliographic citation data retrieved from Scopus were converted into data that could be used for cocitation analysis using Bibexcel software, and then finally analyzed using Net Miner. In total, 523 links were formed and there was no directionality in links between nodes. To confirm the clusters of articles cited together, we carried out community analysis proposed by Blondel et al. [58], which yielded five clusters except for clusters with five or fewer articles (Figure 6). Table 10 shows clusters of articles with high PageRank.

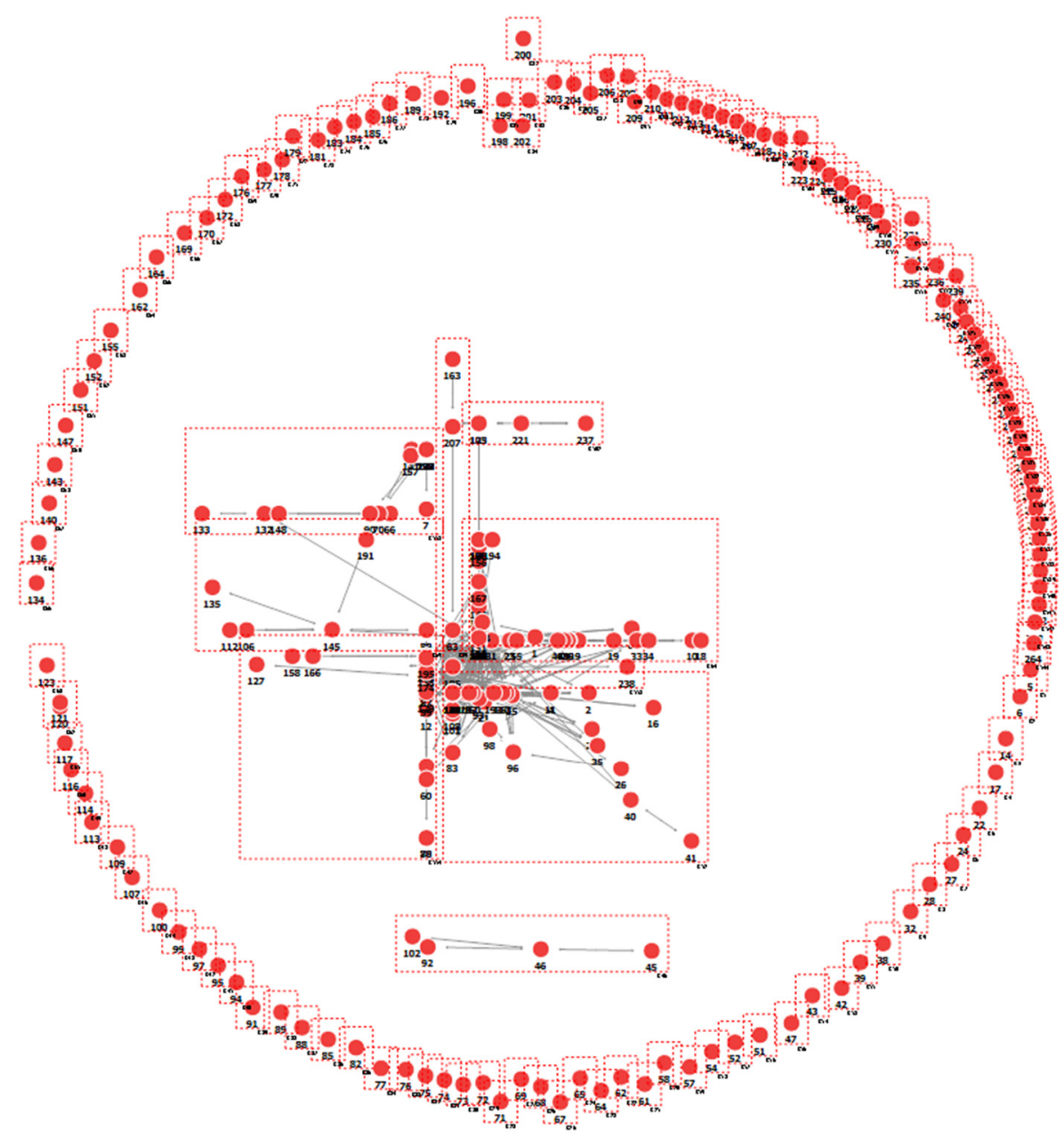

Figure 6. Cocitation network. 
Table 10. Clusters by PageRank analysis.

\begin{tabular}{|c|c|c|}
\hline Clusters & Contributing Articles & Description \\
\hline 1 & $\begin{array}{l}\text { Sheffi [12] } \\
\text { Sheffi and Rice [45] } \\
\text { Xiao et al. [57] } \\
\text { Jüttner [54] }\end{array}$ & $\begin{array}{l}\text { Studies that identify unavoidable risks, such as SC } \\
\text { disruption due to natural disasters or accidents, and } \\
\text { that are concerned with the need for cooperative } \\
\text { relationships between partners in SCs }\end{array}$ \\
\hline 2 & $\begin{array}{l}\text { Beamon and Fernandes [56] } \\
\text { Diabat et al. [59] } \\
\text { Fleischmann et al. [47] }\end{array}$ & $\begin{array}{l}\text { Studies on ensuring ongoing SC management by } \\
\text { building a reverse logistics network that requires } \\
\text { different approaches from those of forward logistics }\end{array}$ \\
\hline 3 & $\begin{array}{l}\text { Blackhurst et al. [29] } \\
\text { Blackhurst et al. [18] } \\
\text { Christopher and Peck [20] } \\
\text { Christopher and Lee [40] } \\
\text { Knemeyer et al. [52] } \\
\text { Braunscheidel and Suresh [55] }\end{array}$ & $\begin{array}{l}\text { Conceptual research to define the concept of SC } \\
\text { resilience and other such concepts related to building } \\
\text { a resilient SC }\end{array}$ \\
\hline 4 & $\begin{array}{l}\text { Faisal, et al. [50] } \\
\text { Jüttner et al. [38] } \\
\text { Peck [46] } \\
\text { Tomlin [42] } \\
\text { Zsidisin et al. [51] } \\
\text { Manuj and Mentzer [53] }\end{array}$ & $\begin{array}{l}\text { Studies on how to identify, manage, and eliminate } \\
\text { risks for SCM }\end{array}$ \\
\hline 5 & $\begin{array}{l}\text { Hendricks and Singhal [43] } \\
\text { Kleindorfer and Saad [39] } \\
\text { Tang [48] } \\
\text { Babich et al. [49] } \\
\text { Qi et al. [60] }\end{array}$ & $\begin{array}{l}\text { Studies on the negative consequences of SC } \\
\text { disruption and countermeasures }\end{array}$ \\
\hline
\end{tabular}

\subsection{Keyword Analysis}

\subsubsection{Analysis of Papers Published by 2012}

While cocitation analysis and PageRank analysis classifies research articles based on citation structures, network keyword analysis allows the determination of studies' topics. We conducted network analysis using keywords provided by authors, because extracting keywords from abstracts makes it difficult to control for additional keywords that are not central to the studies. Extracting keywords from abstracts required calculating the term frequency-inverse document frequency (TF-IDF), because words that appeared often in an abstract may be keywords that are universal in nature [61]. In this study, TF-IDF was not considered, because we used the keywords that the articles listed.

Extracting meaningful frequent keywords requires data cleaning for keywords provided by authors. Data cleaning is very important because cleaned keywords make up individual keyword nodes in the network text analysis. Often, researchers use different keywords with the same meaning. For example, for SC resilience, if author A listed the keyword "SC resilience" while author B listed "resilient SC", we used the single term "SC resilience" for both. To ensure the reliability of data cleaning, we consulted two specialist researchers in $\mathrm{SC}$ research. In the cases of proper nouns consisting of two or more words, we used most of them as they were for keywords. For example, for "supplier selection", we used "supply selection" as one keyword instead of separating it into "supplier" and "selection". In addition, we excluded the words used as search terms from the keyword list. As we searched for "SC resilience", many articles listed "resilience" as a keyword; however, it is difficult to give both the same meaning. Since most of the 825 articles were related to SC resilience, "resilience" could be classified as a word that is universal in nature. This was the same as removing a universal character keyword from the TF-IDF.

To determine research trends using keyword network analysis, we analyzed research articles published over the last five years (2013-2017) and those published earlier (2012 and before). For 
the keyword network analysis, we first constructed a two-mode network that consisted of articles and keywords, and then transformed it into a one-mode network of co-occurring keywords. First, we analyzed 313 articles published by 2012 out of all the SC resilience research that our search yielded in Scopus. The 313 articles yielded 795 keywords. Figure 7 shows the word cloud created based on how often keywords appeared. The frequently listed keywords included flexibility, sustainability, uncertainty, agility, disaster, and simulation.

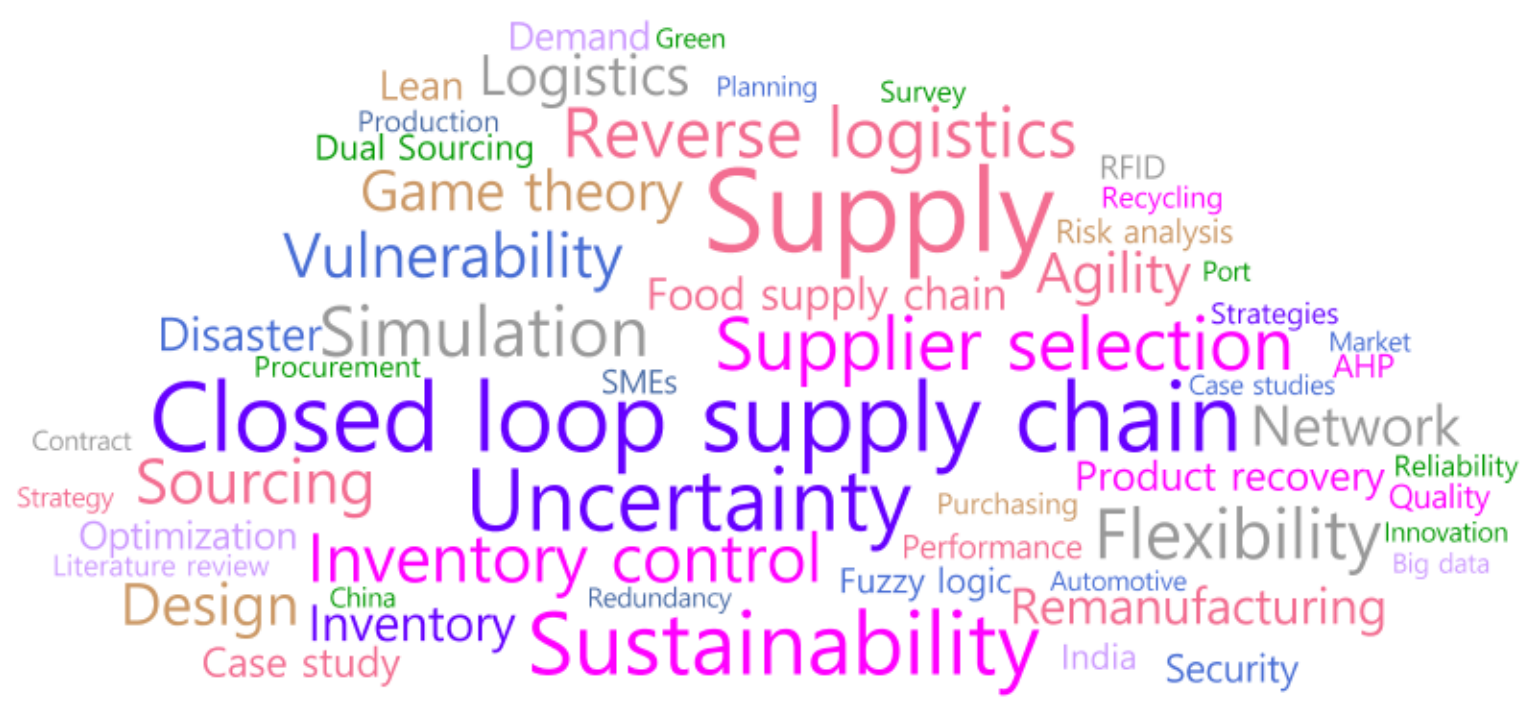

Figure 7. Word cloud of frequent keywords among published articles (2012 and before).

We created a one-mode network with keywords that appeared at least three times among the 795 keywords, using cosine similarity (Equation (4)) as the conversion algorithm and 0.1 as the cutoff value:

$$
\text { Cosine Similarity }=\frac{\sum_{\mathrm{k}=1}^{\mathrm{n}} \mathrm{C}_{\mathrm{ik}} \mathrm{C}_{\mathrm{jk}}}{\sqrt{\sum_{\mathrm{k}=1}^{\mathrm{n}} \mathrm{C}_{\mathrm{ik}}^{2}} \sqrt{\sum_{\mathrm{k}=1}^{\mathrm{n}} \mathrm{C}_{\mathrm{jk}}^{2}}},
$$

where $C_{i}=$ how often keyword $i$ appeared; $C_{j}=$ how often keyword $j$ appeared; $k=$ each research article.

Then, we performed centrality and clustering analyses on the one-mode network. For centrality, we calculated the degree centrality and betweenness centrality. Table 11 shows the degree centrality of keywords. The results show that, in papers published by 2012, the keywords most linked with similar concepts included uncertainty, business continuity, purchasing, design, and sourcing. These keywords represent subtopics of SC resilience research and indicate areas of extensive study. Table 12 shows the betweenness centrality of keywords. The results show that the keywords that mediate sublevel keywords included uncertainty, sustainability, flexibility, supplier selection, SC integration, and purchasing.

Table 11. Results of keyword degree centrality analysis (2012 and before).

\begin{tabular}{cc}
\hline Keyword & Degree Centrality \\
\hline Uncertainty & 0.261538 \\
Business continuity & 0.200000 \\
Purchasing & 0.184615 \\
Design & 0.184615 \\
Sourcing & 0.184615 \\
Empirical research & 0.169231 \\
Case studies & 0.153846 \\
Simulation & 0.153846 \\
Procurement & 0.138462 \\
\hline
\end{tabular}


Table 11. Cont.

\begin{tabular}{|c|c|}
\hline Keyword & Degree Centrality \\
\hline Focus groups & 0.138462 \\
\hline Sustainability & 0.138462 \\
\hline Reverse logistics & 0.138462 \\
\hline Contingency planning & 0.123077 \\
\hline Information sharing & 0.123077 \\
\hline Supplier selection & 0.107692 \\
\hline Logistics & 0.107692 \\
\hline SC coordination & 0.107692 \\
\hline Flexibility & 0.107692 \\
\hline Supply & 0.107692 \\
\hline Information technology & 0.107692 \\
\hline SC integration & 0.092308 \\
\hline Product recovery & 0.092308 \\
\hline Agility & 0.092308 \\
\hline Global sourcing & 0.076923 \\
\hline Inventory control & 0.076923 \\
\hline Disaster & 0.076923 \\
\hline Production & 0.076923 \\
\hline Network & 0.076923 \\
\hline Closed-loop SC & 0.076923 \\
\hline Outsourcing & 0.076923 \\
\hline Case study & 0.061538 \\
\hline Environmental management & 0.061538 \\
\hline Uncertainty management & 0.061538 \\
\hline Security & 0.061538 \\
\hline Strategic planning & 0.061538 \\
\hline SC network & 0.061538 \\
\hline Inventory & 0.061538 \\
\hline Manufacturing industries & 0.061538 \\
\hline Warehousing & 0.046154 \\
\hline China & 0.046154 \\
\hline United Kingdom & 0.046154 \\
\hline Manufacturing & 0.046154 \\
\hline Fuzzy logic & 0.046154 \\
\hline Stochastic programming & 0.046154 \\
\hline Optimal control & 0.046154 \\
\hline Remanufacturing & 0.046154 \\
\hline Vulnerability & 0.046154 \\
\hline Game theory & 0.046154 \\
\hline Lean & 0.046154 \\
\hline Demand & 0.046154 \\
\hline
\end{tabular}

Table 12. Results of keyword betweenness centrality analysis (2012 and before).

\begin{tabular}{cc}
\hline Keyword & Node Betweenness Centrality \\
\hline Uncertainty & 0.124762 \\
Sustainability & 0.123655 \\
Flexibility & 0.095943 \\
Supplier selection & 0.094643 \\
SC integration & 0.080319 \\
Business continuity & 0.07667 \\
Purchasing & 0.071476 \\
Production & 0.066973 \\
\hline
\end{tabular}


Table 12. Cont.

\begin{tabular}{cc}
\hline Keyword & Node Betweenness Centrality \\
\hline Simulation & 0.065881 \\
Design & 0.064901 \\
Empirical research & 0.057637 \\
Product recovery & 0.053706 \\
Reverse logistics & 0.053526 \\
Agility & 0.050867 \\
Sourcing & 0.043434 \\
SC coordination & 0.041485 \\
Contingency planning & 0.038187 \\
Information technology & 0.035228 \\
Case studies & 0.033713 \\
Global sourcing & 0.030193 \\
Disaster & 0.028208 \\
Supply & 0.027276 \\
Logistics & 0.027178 \\
Information sharing & 0.027095 \\
Manufacturing industries & 0.026779 \\
Inventory control & 0.02674 \\
Network & 0.023993 \\
Demand & 0.02386 \\
Security & 0.021302 \\
Inventory & 0.017408 \\
Warehousing & 0.017215 \\
Case study & 0.016068 \\
Game theory & 0.01572 \\
Closed-loop SC & 0.013227 \\
Environmental management & 0.012568 \\
\hline
\end{tabular}

Clustering of research keywords yielded 14 clusters (Figure 8). Table 13 shows the keywords of major clusters that each had at least five keywords and major papers identified based on PageRank. The results show that major papers did not include conceptual studies that provide theoretical frameworks of SC resilience, because keywords, such as "SC resilience" and "resilient SC", were excluded from the analysis.

Table 13. Clusters by keyword network analysis (2012 and before).

\begin{tabular}{cll}
\hline Cluster & \multicolumn{1}{c}{ Major Keyword } & \multicolumn{1}{c}{ Major Paper } \\
\hline \multirow{2}{*}{1} & $\begin{array}{l}\text { Information technology, } \\
\text { Information sharing, SC } \\
\text { coordination, Strategic planning }\end{array}$ & $\begin{array}{l}\text { Li et al. [62] } \\
\text { Qi et al. [60] }\end{array}$ \\
\hline \multirow{2}{*}{2} & $\begin{array}{l}\text { Inventory control, Simulation, } \\
\text { Inventory, Vulnerability }\end{array}$ & Christopher and Lee [40] \\
\hline \multirow{2}{*}{3} & $\begin{array}{l}\text { Agility, SC integration, } \\
\text { Adaptability, Flexibility }\end{array}$ & $\begin{array}{l}\text { Braunscheidel and Suresh [55] } \\
\text { Tomlin [42] } \\
\text { Tang and Tomlin [63] }\end{array}$ \\
\hline \multirow{2}{*}{4} & $\begin{array}{l}\text { Reverse SC, Sustainability, } \\
\text { Manufacturing }\end{array}$ & $\begin{array}{l}\text { Kocabasoglu et al. [64] } \\
\text { Seitz [65] }\end{array}$ \\
\hline \multirow{2}{*}{5} & $\begin{array}{l}\text { Supplier selection, Sourcing, } \\
\text { Uncertainty, Supply, Procurement }\end{array}$ & $\begin{array}{l}\text { Ravindran et al. [66] } \\
\text { Meena et al. [67] }\end{array}$ \\
\hline
\end{tabular}




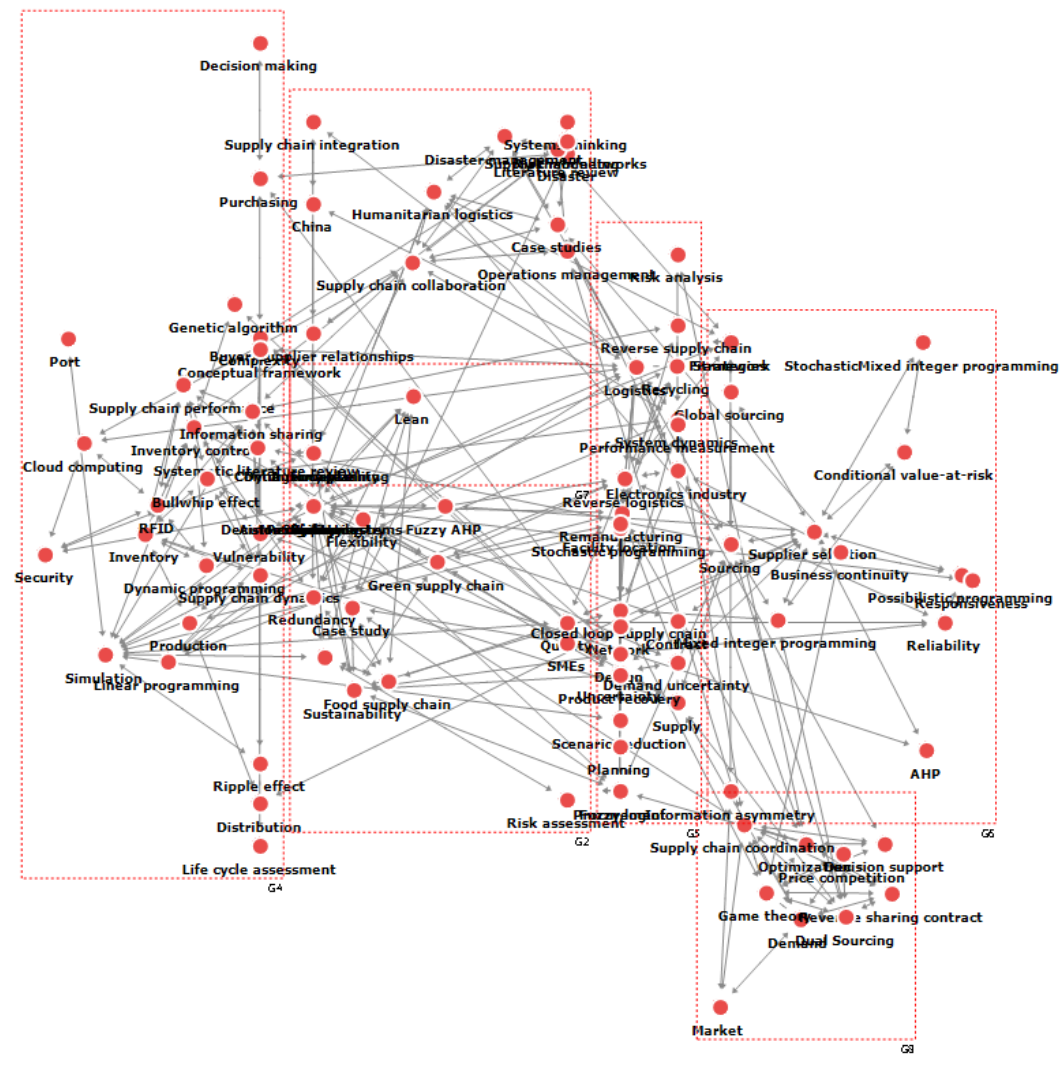

Figure 8. Keyword network (2012 and before).

\subsubsection{Analysis of Papers Published in 2013-2017}

Research trends were identified for the papers published by 2012 and later years (2013 2017) separately through network analysis because the analysis would reveal interesting changes in research concerns over time.

Figure 9 shows major keywords of SC resilience research published between 2013 and 2017. Frequent keywords that emerged after 2012 included "closed-loop SC", "supplier selection", and "reverse logistics". Figure 9 shows the word cloud created based on how often the keywords appeared. Table 14 shows the degree centrality of keywords. The keywords that represented subtopics of SC resilience research since 2013 included "logistics", "closed SC", "reverse logistics", "flexibility", and "supplier selection". As shown in Table 15, the betweenness centrality of keywords suggests that SC resilience research is expanding to such research topics as "SC collaboration" and "SC coordination". The research keywords yielded 14 clusters (Figure 10). Table 16 shows clusters with at least five keywords.

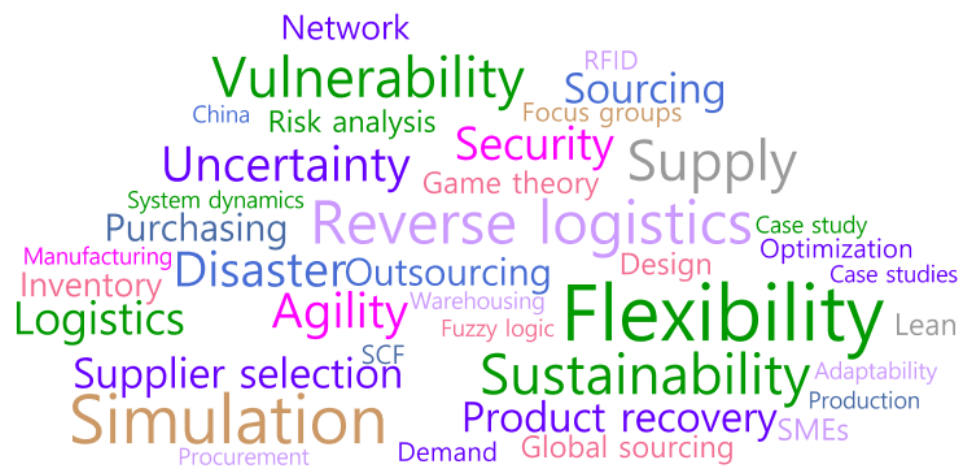

Figure 9. Word cloud of frequent keywords among published articles (2013-2017). 
Table 14. Results of keyword degree centrality analysis (2013-2017).

\begin{tabular}{cc}
\hline Keyword & Degree Centrality \\
\hline Logistics & 0.155963 \\
Closed-loop SC & 0.12844 \\
Flexibility & 0.12844 \\
Reverse logistics & 0.119266 \\
Sourcing & 0.119266 \\
Supplier selection & 0.119266 \\
Simulation & 0.110092 \\
SC coordination & 0.100917 \\
SC collaboration & 0.091743 \\
Design & 0.091743 \\
Remanufacturing & 0.091743 \\
Uncertainty & 0.091743 \\
Sustainability & 0.091743 \\
Vulnerability & 0.091743 \\
Information sharing & 0.082569 \\
Lean & 0.082569 \\
Game theory & 0.082569 \\
Inventory & 0.082569 \\
Agility & 0.082569 \\
Case study & 0.082569 \\
Case studies & 0.073394 \\
Dual Sourcing & 0.073394 \\
System dynamics & 0.073394 \\
Humanitarian logistics & 0.073394 \\
SC dynamics & 0.073394 \\
Inventory control & 0.073394 \\
Electronics industry & 0.06422 \\
Bullwhip effect & 0.06422 \\
SC performance & 0.06422 \\
Automotive industry & 0.06422 \\
Network & 0.06422 \\
Demand & 0.06422 \\
Optimization & 0.06422 \\
Supply & 0.06422 \\
\hline &
\end{tabular}

Table 15. Results of keyword betweenness centrality analysis (2013-2017).

\begin{tabular}{cc}
\hline Keyword & Betweenness Centrality \\
\hline Logistics & 0.116057 \\
Closed-loop SC & 0.091598 \\
Sourcing & 0.086677 \\
Flexibility & 0.082875 \\
Supplier selection & 0.08269 \\
Simulation & 0.070481 \\
SC collaboration & 0.066229 \\
Reverse logistics & 0.061657 \\
Vulnerability & 0.061103 \\
Sustainability & 0.055651 \\
Disaster & 0.05108 \\
Remanufacturing & 0.046358 \\
Uncertainty & 0.044336 \\
Case studies & 0.043048 \\
\hline
\end{tabular}


Table 15. Cont.

\begin{tabular}{cc}
\hline Keyword & Betweenness Centrality \\
\hline Design & 0.041115 \\
System dynamics & 0.039986 \\
Case study & 0.039254 \\
SC coordination & 0.036294 \\
Information sharing & 0.035957 \\
Humanitarian logistics & 0.032933 \\
Inventory control & 0.032337 \\
Supply & 0.031901 \\
Complexity & 0.030222 \\
Agility & 0.025755 \\
Game theory & 0.025718 \\
Green SC & 0.022181 \\
Purchasing & 0.021193 \\
Network & 0.021127 \\
Optimization & 0.020887 \\
\hline
\end{tabular}

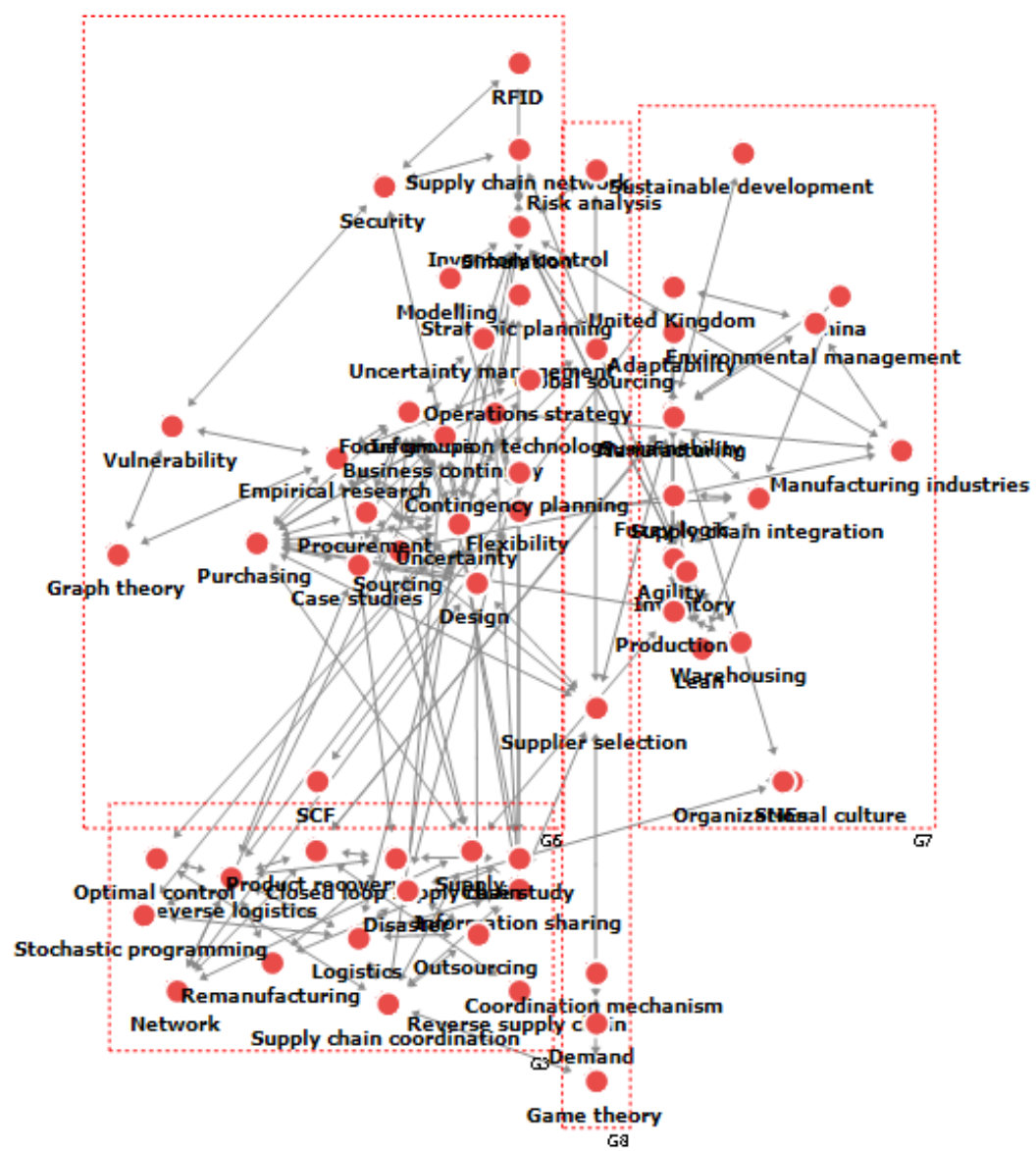

Figure 10. Keyword network (2013-2017). 
Table 16. Clusters by keyword network analysis.

\begin{tabular}{cll}
\hline Cluster & \multicolumn{1}{c}{ Major Keyword } & \multicolumn{1}{c}{ Major Paper } \\
\hline 1 & $\begin{array}{l}\text { Logistics, Strategy, Business } \\
\text { continuity, SC collaboration }\end{array}$ & $\begin{array}{l}\text { Chen et al. [68] } \\
\text { Scholten et al. [31] }\end{array}$ \\
\hline 2 & $\begin{array}{l}\text { Inventory control, Simulation, } \\
\text { Inventory, Bullwhip effect }\end{array}$ & Schmitt et al. [69] \\
\hline 3 & Supply, Game theory & Kim and Tomlin [70] \\
\hline 4 & Supplier selection, Dual sourcing & $\begin{array}{l}\text { Torabi et al. [71] } \\
\text { Rajesh and Ravi [72] } \\
\text { Sawik [73] } \\
\text { Sawik [74] }\end{array}$ \\
\hline 5 & $\begin{array}{l}\text { Closed-loop SC, Demand uncertainty, } \\
\text { Reverse logistics, Flexibility, Agility, }\end{array}$ & $\begin{array}{l}\text { Heckmann et al. [75] } \\
\text { Töyli et al. [76] } \\
\text { Bai and Sarkis [77] }\end{array}$ \\
\hline \multirow{3}{*}{$\begin{array}{l}\text { SC integration } \\
\text { Global sourcing, Information } \\
\text { asymmetry, Buyer/supplier }\end{array}$} & Scholten and Schilder [26] \\
\hline
\end{tabular}

\section{Conclusions}

In this study, we conducted network analysis by retrieving 825 research articles from Scopus and Google Scholar for the search period of 1998-2017 to determine the trends of SC resilience research. The research trends were identified using networks representing coauthorship, PageRank, cocitation, and keywords and are summarized as follows.

First, the results of the analysis performed by converting the two-mode network of research articles and authors into a one-mode network of authors suggest that the researchers who actively engaged in research collaboration through coauthorship were Govindan, K., Craighead, C.W., Wang, S., Blackhurst, J., Wagner, S.M., and Kumar, S. Groups of strong research collaboration in SC resilience research formed around these researchers. In addition, the results of network clustering analysis suggest that such researchers as Govindan, K., Wagner, S.M, Zsidisin, G.A., Diabat, A. Jha, P.C., Ivanov, D., and Craighead, C.W. mediated many research groups.

Second, we were able to determine the relative influence of research articles on the academic community based on weights, rather than simply gauging the citation frequency. The relative importance was analyzed by creating a network of direct citations between articles. The PageRank algorithm affords an article greater influence when cited by a paper that is more frequently cited. The PageRank index was higher for papers published more than five years ago and therefore, they were cited more often. The paper with the highest PageRank index was that of Sheffi [12], who, based on the September 11, 2001 attacks in the United States, emphasized that all systems were inevitably exposed to risk no matter how well prepared, and therefore, they must prepare through extra supplier capacity, extra inventory, and back equipment to both reduce risks in SCM and to cope during and overcome crises. This may be contrary to modern management strategies that value efficiency and lean manufacturing; however, the idea expands to the concept of the resilient SC [20,38-42]. All these papers had a high PageRank index, which suggests that articles that develop theories of $\mathrm{SC}$ resilience have greater relative influence in the field.

Third, the results on the similarity between cited articles obtained from cocitation analysis showed five major clusters. By examining the five clusters focusing on papers with high PageRank, we determined the trends in SC resilience studies. Major clusters included papers on how to identify and control risks in SCM; how to identify what SC risks are difficult to control in advance, such as 
natural disasters, terror attacks, and accidents; how to effectively and quickly respond to SC crises; and in particular, what the negative effects of SC disruption are and how can we recover from it.

Fourth, to identify subtopics in SC resilience research, we conducted separate network text analyses for articles published before, during, or after 2013. The key subtopics of studies published before 2013 were sustainable purchasing and sourcing. Many articles have been about collaboration and information sharing between companies, while improving flexibility, agility, and supplier selection have also been extensively studied. In papers from 2013 or later, the key subtopics were similar to those in previous papers, while closed-loop SC and reverse logistics started drawing attention from researchers. This new trend is likely because closed SCs were studied as a field of sustainable SC research. Building a reverse logistics system increases cooperation and credibility with suppliers and improves logistics and information flow.

Fifth, most SC resilience research concerned collaboration between companies in the SC, improvements in flexibility and agility, and overcoming SC disruptions. Unlike SC research, which often expands on organization theories, such as the resource-based view, complexity theory, institutional theory, transaction cost economics, and social network theory, SC resilience research often defines and empirically analyzes the concept of resilience rather than building on organization theory. Expanding the scope of SC resilience research would require efforts to combine theories.

Lastly, the research trend analysis results indicated that the actively researched area was SC sustainability and confirmed that there are significant interactions between SC resilience and sustainability. Prior studies maintained that existing literatures on sustainable SCM has mostly explained eco-friendly initiatives and considered green SCM practices as critical antecedents for the implementation of sustainable SCM initiatives. However, results of keyword betweenness centrality analysis showed that the research subtopics were expanding around the topics of "sustainability", because the node with a betweenness centrality value has large scalability. Many studies have tried to examine the consequences of SC resilience through a sustainable management lens. This reveals SC resilience capabilities can be a paramount antecedent on the implementation of sustainable SC practices. If SC resilience researchers expand their research scope to the sustainable SC's various subfields, they will give more significant implications for both academia and industry.

Based on the systematic review using network analysis, the following future research is suggested. There is a lack of research on how new information technologies, such as the Internet of things and artificial intelligence, can increase risks in SCs and increase resilience with the advent of the fourth industrial revolution. In addition, practical research that takes recent emerging technological factors into account will likely be required in academia and industry. Research on SC resilience in digital and smart SC should be encouraged. Digital SC deploys emerging smart technologies and requires all operations to be hyperconnected in SC systems. This SC will significantly enhance efficiency, speed, and flexibility with a standards-based, scalable, security-rich solutions. However, if the entire system is unstable and collapses at once due to a complex network structure, it can lead to a great crisis. This system vulnerability is in line with normal accident theory. Some papers have maintained that blockchain technology can play a critical role in enhancing SC resilience and mitigating the risk of cybercrime and hacking in smart SC systems [79]. SC resilience researchers need to develop a better understanding of smart SC and emerging technologies in the Industry 4.0 era.

Moreover, future research will need to apply several different methodologies, such as network analysis, and process mining techniques to extend of the scope of previous studies. Researchers have mainly employed methodologies including optimization, simulation, and regression. Even though SC can be defined as a network of suppliers and buyers [80], a few studies have focused on how network structure and flow processes impact on SC disruption and resilience. In terms of SC network structure, SC risk factors can be classified into three types: node-level, arc-level, and network-level risks [81]. Resilience to each risk is significantly associated with the network centralization level and betweenness centrality $[80,81]$. Another way of mapping out a SC network is process mining. Petri net, a representative process mining technique, is measuring structure and flow in SC networks [82]. 
Petri net is valuable to quantify multitiered supply processes and measure propagation aspects of real-life SC disruption events. In this respect, network analysis and process mining approaches can be used effectively to investigate SC resilience, especially in today's globalized and complex SC systems [83].

The implications of this study are as follows. First, we conducted a systematic trend analysis of SC resilience research and presented research trends. While research trend analyses on SC risk management exist, no existing study has conducted network analysis focused on recovery from SC crises. Through the network analyses of papers included in Scopus-a highly reputable database of published articles-we identified the key content and author groups of SC resilience research. The findings are expected to help expand the scope of research to a wide range of subfields in SC resilience research in the future. Second, the present study provided a systematic approach to research trend analysis. Whereas conventional research trend analyses simply involve obtaining statistics based on criteria about relevant studies or classifying articles based on the researcher's subjective criteria, the present study employed various approaches, including analyses of coauthorship, cocitation, the relative influence of the paper, clustering, and network keyword analysis using network analysis. Moreover, unlike existing studies on research trends that utilized network analyses and tended to focus on keyword network analysis, this study offered research trend network analyses from various perspectives. This study employed a method that has significant implications for researchers who intend to perform research trend analysis in the future. In particular, the clustering of authors and analyses of the influence of individual papers based on the PageRank algorithm in this study is likely to have significant ramifications for researchers.

This study has the following limitations. First, since we performed analyses on articles in Scopus, our analysis could omit the SC resilience studies not included in Scopus. To address this concern, we searched Google Scholar and added missing major articles to our analyses; however, we may still have missed some papers, because we added those based on the citation frequency offered by Google Scholar. Second, due to the use of keywords listed in research articles for keyword network analysis and the various ways authors choose their keywords, certain keywords might not have been fully incorporated into the studies' characteristics. In fact, some studies were very similar in topic and content but listed different keywords. To remove such errors, research trends are sometimes analyzed by analyzing papers' abstracts. In the present study, we tried to eliminate errors in keyword selection by conducting data cleaning on keywords and verifying the correspondence between the study's content and keywords through consultation with service research experts. However, if the keywords listed in articles were not representative of their studies, the results of our analysis might have limitations. Third, this study did not analyze studies' research methods. Future research trend analyses should conduct a two-mode network analysis for a method-paper pair and a method-author pair.

Funding: This research received no external funding.

Conflicts of Interest: The author declares no conflict of interest.

\section{References}

1. Tang, C.S.; Zimmerman, J.D.; Nelson, J.I. Managing new product development and supply chain risks: The Boeing 787 case. Supply Chain Forum Int. J. 2009, 10, 74-86. [CrossRef]

2. MacKenzie, C.A.; Barker, K.; Santos, J.R. Modeling a severe supply chain disruption and post-disaster decision making with application to the Japanese earthquake and tsunami. IIE Trans. 2014, 46, 1243-1260. [CrossRef]

3. Fahimnia, B.; Tang, C.S.; Davarzani, H.; Sarkis, J. Quantitative models for managing supply chain risks: A review. Eur. J. Oper. Res. 2015, 247, 1-15. [CrossRef]

4. Perrow, C. The organizational context of human factors engineering. Adm. Sci. Q. 1983, 28, 521-541. [CrossRef]

5. Perrow, C. Normal accident at Three Mile Island. Society 1981, 18, 17-26. [CrossRef] 
6. Carter, C.R.; Rogers, D.S. A framework of sustainable supply chain management: Moving toward new theory. Int. J. Phys. Distrib. Logist. Manag. 2008, 38, 360-387. [CrossRef]

7. Singh, A.; Trivedi, A. Sustainable green supply chain management: Trends and current practices. Compet. Rev. 2016, 25, 265-288. [CrossRef]

8. Papadopoulos, T.; Gunasekaran, A.; Dubey, R.; Altay, N.; Childe, S.J.; Fosso-Wamba, S. The role of Big Data in explaining disaster resilience in supply chains for sustainability. J. Clean. Prod. 2017, 142, 1108-1118. [CrossRef]

9. Ivanov, D. Revealing interfaces of supply chain resilience and sustainability: A simulation study. Int. J. Prod. Res. 2018, 56, 3507-3523. [CrossRef]

10. Holling, C.S. Resilience and stability of ecological systems. Annu. Rev. Ecol. Syst. 1973, 4, 1-23. [CrossRef]

11. Hamel, G.; Välikangas, L. Why resilience matters. Harv. Bus. Rev. 2003, 81, 56-57.

12. Sheffi, Y. The Resilient Enterprise: Overcoming Vulnerability for Competitive Advantage; MIT Press Books: Boston, MA, USA, 2005.

13. Sutcliffe, K.M.; Vogus, T.J. Organizing for resilience. Posit. Organ. Scholarsh. Found. A New Discip. 2003, 94, 110.

14. Colicchia, C.; Dallari, F.; Melacini, M. Increasing supply chain resilience in a global sourcing context. Prod. Plan. Control 2010, 21, 680-694. [CrossRef]

15. Jüttner, U.; Maklan, S. Supply chain resilience in the global financial crisis: An empirical study. Supply Chain Manag. 2011, 16, 246-259. [CrossRef]

16. Datta, S.; Granger, C.W.J.; Barari, M.; Gibbs, T. Management of supply chain: An alternative modelling technique for forecasting. J. Oper. Res. Soc. 2007, 58, 1459-1469. [CrossRef]

17. Brandon-Jones, E.; Squire, B.; Autry, C.W.; Petersen, K.J. A contingent resource-based perspective of supply chain resilience and robustness. J. Supply Chain Manag. 2014, 50, 55-73. [CrossRef]

18. Blackhurst, J.; Craighead, C.W.; Elkins, D.; Handfield, R.B. An empirically derived agenda of critical research issues for managing supply-chain disruptions. Int. J. Prod. Res. 2005, 43, 4067-4081. [CrossRef]

19. Lee, H.L. The triple-A supply chain. Harv. Bus. Rev. 2004, 82, 102-113.

20. Christopher, M.; Peck, H. Building the resilient supply chain. Int. J. Logist. Manag. 2004, 15, 1-13. [CrossRef]

21. Pettit, T.J.; Fiksel, J.; Croxton, K.L. Ensuring supply chain resilience: Development of a conceptual framework. J. Bus. Logist. 2010, 31, 1-21. [CrossRef]

22. Maria Jesus Saenz, P.; Xenophon Koufteros, D.; Hohenstein, N.; Feisel, E.; Hartmann, E.; Giunipero, L. Research on the phenomenon of supply chain resilience: A systematic review and paths for further investigation. Int. J. Phys. Distrib. Logist. Manag. 2015, 45, 90-117.

23. Sreedevi, R.; Saranga, H. Uncertainty and supply chain risk: The moderating role of supply chain flexibility in risk mitigation. Int. J. Prod. Econ. 2017, 193, 332-342. [CrossRef]

24. Lee, S.M.; Rha, J.S. Ambidextrous supply chain as a dynamic capability: Building a resilient supply chain. Manag. Decis. 2016, 54, 2-23. [CrossRef]

25. Kim, M.; Chai, S. The impact of supplier innovativeness, information sharing and strategic sourcing on improving supply chain agility: Global supply chain perspective. Int. J. Prod. Econ. 2017, 187, 42-52. [CrossRef]

26. Scholten, K.; Schilder, S. The role of collaboration in supply chain resilience. Supply Chain Manag. 2015, 20, 471-484. [CrossRef]

27. Cao, M.; Vonderembse, M.A.; Zhang, Q.; Ragu-Nathan, T.S. Supply chain collaboration: Conceptualisation and instrument development. Int. J. Prod. Res. 2010, 48, 6613-6635. [CrossRef]

28. Pettit, T.J.; Croxton, K.L.; Fiksel, J. Ensuring supply chain resilience: Development and implementation of an assessment tool. J. Bus. Logist. 2013, 34, 46-76. [CrossRef]

29. Blackhurst, J.; Dunn, K.S.; Craighead, C.W. An empirically derived framework of global supply resiliency. J. Bus. Logist. 2011, 32, 374-391. [CrossRef]

30. Kern, D.; Moser, R.; Hartmann, E.; Moder, M. Supply risk management: Model development and empirical analysis. Int. J. Phys. Distrib. Logist. Manag. 2012, 42, 60-82. [CrossRef]

31. Scholten, K.; Scott, P.S.; Fynes, B. Mitigation processes-Antecedents for building supply chain resilience. Supply Chain Manag. Int. J. 2014, 19, 211-228. [CrossRef] 
32. Fahimnia, B.; Sarkis, J.; Davarzani, H. Green supply chain management: A review and bibliometric analysis. Int. J. Prod. Econ. 2015, 162, 101-114. [CrossRef]

33. Feng, Y.; Zhu, Q.; Lai, K.H. Corporate social responsibility for supply chain management: A literature review and bibliometric analysis. J. Clean. Prod. 2017, 158, 296-307. [CrossRef]

34. Mishra, D.; Gunasekaran, A.; Papadopoulos, T.; Hazen, B. Green supply chain performance measures: A review and bibliometric analysis. Sustain. Prod. Consum. 2017, 10, 85-99. [CrossRef]

35. Lee, S.M.; Rha, J.S. A network text analysis of published papers in service business, 2007-2017: Research trends in the service sector. Serv. Bus. 2018, 12, 809-831. [CrossRef]

36. Brin, S.; Page, L. The anatomy of a large-scale hypertextual Websearch engine. Comput. Netw. 1998, 30, 107-117.

37. Ding, Y. Applying weighted PageRank to author citation networks. J. Am. Soc. Inf. Sci. Technol. 2011, 62, 236-245. [CrossRef]

38. Jüttner, U.; Peck, H.; Christopher, M. Supply chain risk management: Outlining an agenda for future research. Int. J. Logist. Res. Appl. 2003, 6, 197-210. [CrossRef]

39. Kleindorfer, P.R.; Saad, G.H. Managing disruption risks in supply chains. Prod. Oper. Manag. 2005, 14, 53-68. [CrossRef]

40. Christopher, M.; Lee, H. Mitigating supply chain risk through improved confidence. Int. J. Phys. Distrib. Logist. Manag. 2004, 34, 388-396. [CrossRef]

41. Craighead, C.W.; Blackhurst, J.; Rungtusanatham, M.J.; Handfield, R.B. The severity of supply chain disruptions: Design characteristics and mitigation capabilities. Decis. Sci. 2007, 38, 131-156. [CrossRef]

42. Tomlin, B. On the value of mitigation and contingency strategies for managing supply chain disruption risks. Manag. Sci. 2006, 52, 639-657. [CrossRef]

43. Hendricks, K.B.; Singhal, V.R. An empirical analysis of the effect of supply chain disruptions on long-run stock price performance and equity risk of the firm. Prod. Oper. Manag. 2005, 14, 35-52. [CrossRef]

44. Tang, C.S. Perspectives in supply chain risk management. Int. J. Prod. Econ. 2006, 103, 451-488. [CrossRef]

45. Sheffi, Y.; Rice, J.B., Jr. A supply chain view of the resilient enterprise. Mit Sloan Manag. Rev. 2005, 47, 41.

46. Peck, H. Drivers of supply chain vulnerability: An integrated framework. Int. J. Phys. Distrib. Logist. Manag. 2005, 35, 210-232. [CrossRef]

47. Fleischmann, M.; Beullens, P.; Bloemhof-Ruwaard, J.M.; Van Wassenhove, L.N. The impact of product recovery on logistics network design. Prod. Oper. Manag. 2001, 10, 156-173. [CrossRef]

48. Tang, C.S. Robust strategies for mitigating supply chain disruptions. Int. J. Logist. Res. Appl. 2006, 9, $33-45$. [CrossRef]

49. Babich, V.; Burnetas, A.N.; Ritchken, P.H. Competition and diversification effects in supply chains with supplier default risk. Manuf. Serv. Oper. Manag. 2007, 9, 123-146. [CrossRef]

50. Nishat Faisal, M.; Banwet, D.; Shankar, R. Information risks management in supply chains: An assessment and mitigation framework. J. Enterp. Inf. Manag. 2007, 20, 677-699. [CrossRef]

51. Zsidisin, G.; Ellram, L.; Carter, J.; Cavinato, J. An analysis of supply risk assessment techniques. Int. J. Phys. Distrib. Logist. Manag. 2004, 34, 397-413. [CrossRef]

52. Knemeyer, A.M.; Zinn, W.; Eroglu, C. Proactive planning for catastrophic events in supply chains. J. Oper. Manag. 2009, 27, 141-153. [CrossRef]

53. Manuj, I.; Mentzer, J.T. Global supply chain risk management strategies. Int. J. Phys. Distrib. Logist. Manag. 2008, 38, 192-223. [CrossRef]

54. Jüttner, U. Supply chain risk management: Understanding the business requirements from a practitioner perspective. Int. J. Logist. Manag. 2005, 16, 120-141. [CrossRef]

55. Braunscheidel, M.J.; Suresh, N.C. The organizational antecedents of a firm's supply chain agility for risk mitigation and response. J. Oper. Manag. 2009, 27, 119-140. [CrossRef]

56. Beamon, B.M.; Fernandes, C. Supply-chain network configuration for product recovery. Prod. Plan. Control 2004, 15, 270-281. [CrossRef]

57. Xiao, T.; Qi, X.; Yu, G. Coordination of supply chain after demand disruptions when retailers compete. Int. J. Prod. Econ. 2007, 109, 162-179. [CrossRef]

58. Blondel, V.D.; Guillaume, J.L.; Lambiotte, R.; Lefebvre, E. Fast unfolding of communities in large networks. J. Stat. Mech. Theory Exp. 2008, 2008, P10008. [CrossRef] 
59. Diabat, A.; Abdallah, T.; Al-Refaie, A.; Svetinovic, D.; Govindan, K. Strategic closed-loop facility location problem with carbon market trading. IEEE Trans. Eng. Manag. 2012, 60, 398-408. [CrossRef]

60. Qi, X.; Bard, J.F.; Yu, G. Supply chain coordination with demand disruptions. Omega 2004, 32, 301-312. [CrossRef]

61. Ramos, J. Using TF-IDF to determine word relevance in document queries. In Proceedings of the First Instructional Conference on Machine Learning, Piscataway, NJ, USA, 3-8 December 2003; Volume 242, pp. 133-142.

62. Li, J.; Wang, S.; Cheng, T.E. Competition and cooperation in a single-retailer two-supplier supply chain with supply disruption. Int. J. Prod. Econ. 2010, 124, 137-150. [CrossRef]

63. Tang, C.; Tomlin, B. The power of flexibility for mitigating supply chain risks. Int. J. Prod. Econ. 2008, 116, 12-27. [CrossRef]

64. Kocabasoglu, C.; Prahinski, C.; Klassen, R.D. Linking forward and reverse supply chain investments: The role of business uncertainty. J. Oper. Manag. 2007, 25, 1141-1160. [CrossRef]

65. Seitz, M.A. A critical assessment of motives for product recovery: The case of engine remanufacturing. J. Clean. Prod. 2007, 15, 1147-1157. [CrossRef]

66. Ravindran, A.R.; Ufuk Bilsel, R.; Wadhwa, V.; Yang, T. Risk adjusted multicriteria supplier selection models with applications. Int. J. Prod. Res. 2010, 48, 405-424. [CrossRef]

67. Meena, P.L.; Sarmah, S.P.; Sarkar, A. Sourcing decisions under risks of catastrophic event disruptions. Transp. Res. Part E Logist. Transp. Rev. 2011, 47, 1058-1074. [CrossRef]

68. Chen, J.; Sohal, A.S.; Prajogo, D.I. Supply chain operational risk mitigation: A collaborative approach. Int. J. Prod. Res. 2013, 51, 2186-2199. [CrossRef]

69. Schmitt, A.J.; Sun, S.A.; Snyder, L.V.; Shen, Z.J.M. Centralization versus decentralization: Risk pooling, risk diversification, and supply chain disruptions. Omega 2015, 52, 201-212. [CrossRef]

70. Kim, S.H.; Tomlin, B. Guilt by association: Strategic failure prevention and recovery capacity investments. Manag. Sci. 2013, 59, 1631-1649. [CrossRef]

71. Torabi, S.A.; Baghersad, M.; Mansouri, S.A. Resilient supplier selection and order allocation under operational and disruption risks. Transp. Res. Part E Logist. Transp. Rev. 2015, 79, 22-48. [CrossRef]

72. Rajesh, R.; Ravi, V. Supplier selection in resilient supply chains: A grey relational analysis approach. J. Clean. Prod. 2015, 86, 343-359. [CrossRef]

73. Sawik, T. Joint supplier selection and scheduling of customer orders under disruption risks: Single vs. dual sourcing. Omega 2014, 43, 83-95. [CrossRef]

74. Sawik, T. Selection of resilient supply portfolio under disruption risks. Omega 2013, 41, 259-269. [CrossRef]

75. Heckmann, I.; Comes, T.; Nickel, S. A critical review on supply chain risk—Definition, measure and modeling. Omega 2015, 52, 119-132. [CrossRef]

76. Töyli, H.L.; Lauri Ojala, J.; Wieland, A.; Marcus Wallenburg, C. The influence of relational competencies on supply chain resilience: A relational view. Int. J. Phys. Distrib. Logist. Manag. 2013, 43, 300-320.

77. Bai, C.; Sarkis, J. Flexibility in reverse logistics: A framework and evaluation approach. J. Clean. Prod. 2013, 47, 306-318. [CrossRef]

78. Bode, C.; Wagner, S.M. Structural drivers of upstream supply chain complexity and the frequency of supply chain disruptions. J. Oper. Manag. 2015, 36, 215-228. [CrossRef]

79. Min, H. Blockchain technology for enhancing supply chain resilience. Bus. Horiz. 2019, 62, 35-45. [CrossRef]

80. Choi, T.Y.; Dooley, K.J.; Rungtusanatham, M. Supply networks and complex adaptive systems: Control versus emergence. J. Oper. Manag. 2001, 19, 351-366. [CrossRef]

81. Kim, Y.; Chen, Y.S.; Linderman, K. Supply network disruption and resilience: A network structural perspective. J. Oper. Manag. 2015, 33-34, 43-59. [CrossRef] 
82. Blackhurst, J.; Rungtusanatham, M.J.; Scheibe, K.; Ambulkar, S. Supply chain vulnerability assessment: A network based visualization and clustering analysis approach. J. Purch. Supply Manag. 2018, 24, 21-30. [CrossRef]

83. Wang, J.W.; Ip, W.H.; Muddada, R.R.; Huang, J.L.; Zhang, W.J. On Petri net implementation of proactive resilient holistic supply chain networks. Int. J. Adv. Manuf. Technol. 2013, 69, 427-437. [CrossRef]

(C) 2020 by the author. Licensee MDPI, Basel, Switzerland. This article is an open access article distributed under the terms and conditions of the Creative Commons Attribution (CC BY) license (http://creativecommons.org/licenses/by/4.0/). 